\title{
BMJ Open Comparison of cerebral blood flow in subjects with and without chronic obstructive pulmonary disease from the population-based Rotterdam Study
}

\author{
Sara R A Wijnant (10 , 1,2,3 Daniel Bos, ${ }^{2,4,5}$ Guy Brusselle,, ${ }^{1,2,6}$ Maxim Grymonprez, ${ }^{3}$ \\ Ernst Rietzschel, ${ }^{7}$ Meike W Vernooij, ${ }^{2,4}$ Natalie Terzikhan, ${ }^{2}$ Lies Lahousse (1) ${ }^{2,3}$
}

To cite: Wijnant SRA,

Bos D, Brusselle G, et al. Comparison of cerebral blood flow in subjects with and without chronic obstructive pulmonary disease from the population-based Rotterdam Study. BMJ Open 2021;11:e053671. doi:10.1136/ bmjopen-2021-053671

- Prepublication history and additional supplemental material for this paper are available online. To view these files, please visit the journal online (http://dx.doi.org/10.1136/ bmjopen-2021-053671)

NT and LL contributed equally.

Received 24 May 2021

Accepted 24 November 2021

Check for updates

(C) Author(s) (or their employer(s)) 2021. Re-use permitted under CC BY-NC. No commercial re-use. See rights and permissions. Published by BMJ.

For numbered affiliations see end of article.

Correspondence to

Dr Lies Lahousse;

lies.lahousse@ugent.be

\section{ABSTRACT}

Objectives Patients with chronic obstructive pulmonary disease (COPD) are at increased risk of cerebrovascular disease, which might be associated with decreases in cerebral blood flow. Since studies examining cerebral blood flow in COPD remain scarce and are limited by sample size, we aimed to study cerebral blood flow in participants with and without COPD.

Design Observational cohort study.

Setting Population-based Rotterdam Study.

Participants 4177 participants (age $68.0 \pm 8.5$ years; $53 \%$ females) with and without COPD.

Predictor variable Spirometry and pulmonary diffusing capacity.

Outcome measures Cerebral blood flow by twodimensional phase-contrast cerebral MRI.

Results Compared with subjects with normal spirometry

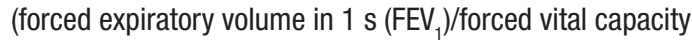
(FVC) $\geq 0.7$ and $\mathrm{FEV}_{1} \geq 80 \%$ ), multivariable adjusted cerebral blood flow ( $\mathrm{mL} / \mathrm{min}$ ) was preserved in subjects with COPD Global initiative for Chronic Obstructive Lung Disease (GOLD1) (FEV/FVC $<0.7$ and $\mathrm{FEV}_{1} \geq 80 \%$ ), but significantly lower in subjects with COPD GOLD2-3 (FEV $/$ $\mathrm{FVC}<0.7$ and $\mathrm{FEV}_{1}<80 \%$ ), even after adjustment for cardiovascular comorbidities. In sex-stratified analyses, this difference in cerebral blood flow was statistically significant in women but not in men. Cerebral blood flow was lowest in subjects with $\mathrm{FEV}_{1}, \mathrm{FVC}$ and diffusion lung capacity for carbon monoxide \% predicted values in the lowest quintile, even after adjustment for cardiovascular comorbidities and cardiac function.

Conclusion We observed a lowered cerebral blood flow in subjects with COPD GOLD2-3.

\section{INTRODUCTION}

Increasing evidence suggests a link between chronic obstructive pulmonary disease (COPD) and cerebrovascular disease, including cerebral microbleeds and stroke. ${ }^{1-3}$ Elucidating aetiological pathways linking lung function impairment to cerebrovascular disease is crucial in order to identify patients who are at risk for worse outcomes, and who may benefit from preventive interventions.
Strengths and limitations of this study

- The population-based nature of the Rotterdam Study minimises the risk for selection bias.

- The large number of participants in this study allowed us to perform multivariable adjustments in regression analyses, reducing the risk of confounding bias.

By using data from the fifth round of the Rotterdam Study, a healthy survivor effect may dilute and underestimate the effect between predictor and outcome.

- Residual confounding could be due to unmeasured intracranial stenotic lesions or variability in arterial blood gasses, for which we were unable to adjust for.

Observations from large epidemiological studies indicate that a decrease in cerebral blood flow may precede cerebrovascular diseases, such as transient ischaemic attacks, ${ }^{4}$ but also dementia. ${ }^{5-9}$ Cerebral hypoperfusion can be elicited by arterial stiffening, ${ }^{10}$ which has been associated with airflow limitation as well. ${ }^{11}{ }^{12}$ Moreover, left ventricular filling has been shown to be reduced in subjects with COPD,${ }^{13}$ which in turn may result in reduced cerebral blood flow. Hence, we hypothesised that subjects with COPD have impaired cerebral blood flow. If true, this could contribute to their predisposition for worse cerebrovascular outcomes. However, to date, studies examining cerebral blood flow in subjects with COPD were limited by their small sample size, and none of the studies measured cerebral blood flow by means of brain MRI scans. To this end, we aimed to compare cerebral blood flow between a large number of subjects with normal spirometry, mild COPD (COPD Global initiative for Chronic Obstructive Lung Disease (GOLD1)) and moderateto-severe COPD (COPD GOLD2-3), as well 
as the lowest quintiles of forced expiratory volume in $1 \mathrm{~s}$ $\left(\mathrm{FEV}_{1}\right)$, forced vital capacity (FVC), diffusion lung capacity for carbon monoxide (DLCO) and DLCO adjusted for alveolar volume percent predicted in different quintiles.

\section{METHODS}

\section{Study design and study population}

This study was embedded within the Rotterdam Study, a population-based prospective cohort study that started in 1989 and aimed at investigating the incidence and risk factors for chronic diseases in the elderly. ${ }^{14}$ Residents of the Ommoord district in Rotterdam were invited every 3-4 years to the research centre for follow-up examinations. The current study included measurements from the fifth round of the Rotterdam Study (2009-2013). Participants were eligible for inclusion when having interpretable measures for lung function (spirometry or diffusion capacity) and cerebral blood flow.

\section{Spirometry and lung diffusing capacity}

Prebronchodilator spirometry was performed by trained paramedical personnel using a Master Screen PFT Pro (Care Fusion, Netherlands) according to the European Respiratory Society/American Thoracic Society (ERS/ ATS) guidelines. Predicted FEV $_{1}$ and FVC values were calculated using global lung initiative reference equations taking age, sex, height and ethnicity into account. ${ }^{15}$ COPD cases were defined as having an obstructive spirometry $\left(\mathrm{FEV}_{1} / \mathrm{FVC}<0.7\right) .{ }^{16}$ Severity of obstruction was determined according to the modified GOLD criteria: mild COPD (GOLD1, $\mathrm{FEV}_{1} \geq 80 \%$ ) and moderate to severe COPD (GOLD2-3, $\mathrm{FEV}_{1}<80 \%$ ). DLCO (mmol/ $\mathrm{min} / \mathrm{kPA}$ ) was measured by the single-breath technique in accordance with ERS/ATS guidelines. ${ }^{17}$ For this study, DLCO was not corrected for haemoglobin.

\section{Cerebral blood flow and cerebral blood perfusion}

Using a 1.5 T brain MRI scanner (Signa Excite II; General Electric Healthcare, Milwaukee, Wisconsin, USA) we obtained cerebral blood flow measurements. An eightchannel head coil was used for reception of the signal. For flow measurement, a sagittal two-dimensional phasecontrast MRI angiographic scout image was performed (repetition time $=24 \mathrm{~ms}$, echo time $=9 \mathrm{~ms}$, field of view $=32$ $\mathrm{cm}^{2}$, matrix $=256$; 160 , flip angle $=101$, number of excitations $=1$, bandwidth $=8.06 \mathrm{kHz}$, velocity encoding $=60$ $\mathrm{cm} / \mathrm{s}$, and slice thickness $=60 \mathrm{~mm})$. Acquisition time was $12 \mathrm{~s}$. On this scout image, a transverse imaging plane perpendicular to both the precavernous portion of the internal carotid arteries and the middle part of the basilar artery was chosen for a two-dimensional gradient-echo phase-contrast sequence (repetition time $=20 \mathrm{~ms}$, echo time $=4 \mathrm{~ms}$, field of view $=19 \mathrm{~cm}^{2}$, matrix $=256 ; 160$, flip angle $=81$, number of excitations $=8$, bandwidth $=22.73$ $\mathrm{kHz}$, velocity encoding $=120 \mathrm{~cm} / \mathrm{s}$, and slice thickness $=5$ $\mathrm{mm})$. Acquisition time was $51 \mathrm{~s}$, and no cardiac gating was performed. Flow $(\mathrm{mL} / \mathrm{s})$ was calculated by multiplying the average velocity with the cross-sectional area of the vessel. Flow rates were summed and multiplied by 60 $\mathrm{s} / \mathrm{min}$ to get total cerebral blood flow $(\mathrm{mL} / \mathrm{min})$. To measure cerebral blood perfusion $(\mathrm{mL} / 100 \mathrm{~mL} / \mathrm{min})$, values were divided by each individual's brain volume $(\mathrm{mL})$, and the obtained results were multiplied by $100{ }^{18}$ For the assessment of brain volumes, the structural MRI scans (T1-weighted, proton density-weighted and fluid-attenuated inversion recovery) were used. Details, including preprocessing steps and the classification algorithm, have been described elsewhere. ${ }^{19}$

\section{Covariables}

Smoking status (never, former, current) and pack-years (years smoked multiplied by daily number of smoked cigarettes divided by 20) were assessed by interview. Hypertension was defined as a systolic blood pressure $\geq 140 \mathrm{~mm}$ $\mathrm{Hg}$, a diastolic blood pressure $\geq 90 \mathrm{~mm} \mathrm{Hg}$, or the use of blood pressure-lowering drugs. Clinical diagnosis of heart failure and stroke were based on active follow-up using the medical records of the participants. ${ }^{20}{ }^{21}$ Coronary heart disease included myocardial infarction, coronary artery bypass grafting, and percutaneous coronary intervention. ${ }^{20}$ Diabetes was defined as a fasting plasma glucose level $\geq 7 \mathrm{mmol} / \mathrm{L}$, a non-fasting plasma glucose level $\geq$ $11.1 \mathrm{mmol} / \mathrm{L}$ or the use of glucose-lowering medication. Haemodynamically significant carotid artery stenosis was defined as a $\geq 50 \%$ reduction in lumen diameter measured by duplex ultrasonography at the level of the left or right internal carotid arteries, common carotid arteries or bifurcation of the carotid arteries. ${ }^{22}$ Estimated glomerular filtration rate (eGFR) was obtained based on the formula as provided by the Chronic Kidney Disease Epidemiology Collaboratio. ${ }^{23}$ Apolipoprotein E (APOE) genotype was determined using a PCR in the original cohort (RS-I) and a bi-allelic TaqMan assay (rs7412 and rs429358) on labelled DNA samples in the extended cohorts (RS-II-3 and RS-III-2), respectively. APOE- 84 represented carrier of one or two $\varepsilon 4$ alleles. Participants were categorised into three groups: high genetic risk ( $\varepsilon 2 \varepsilon 4, \varepsilon 3 \varepsilon 4$ or $\varepsilon 4 \varepsilon 4$ genotypes), intermediate risk ( $\varepsilon 3 \varepsilon 3)$ or low risk $(\varepsilon 2 \varepsilon 2$ or $\varepsilon 2 \varepsilon 3) .{ }^{24}$ Information on medication use was obtained from interview and from pharmacies. Blood samples for the determination of levels of serum glucose, cholesterol, haemoglobin and DNA were measured using an automated enzymatic method.

\section{Statistical analysis}

We compared participant characteristics using Student's t-test for parametric continuous variables, Mann-Whitney $\mathrm{U}$ test for non-parametric continuous variables and $\chi^{2}$ test for categorical variables. Subjects with normal spirometry or with lung function values in the highest quintile were the reference category for multivariable adjusted linear regression analyses with cerebral blood flow as outcome variable. Covariables for these multivariable adjusted linear regression analyses were selected based on clinical relevance, literature knowledge and availability of 
the data. Models were adjusted for age, sex, body mass index, current smoking, haemoglobin, white cell count, glucose, eGFR, heart rate, hypertension, heart failure, coronary heart disease, diabetes and carotid artery stenosis. Missing values for heart failure, coronary heart disease, diabetes and carotid artery stenosis were assigned 'non-informative' and included in the models. Log transformation was considered for right skewed continuous variables. Nonlinearity of continuous variables was tested using second degree natural spline polynomials and nonlinear terms were added if improving the model. A two-sided $\mathrm{p}<0.05$ was considered statistically significant. We used R V.3.6.1 (Foundation for Statistical Computing, Vienna, Austria).

\section{Patient and public involvement}

Participants and members of the public were not involved in the design, management, or conduct of the study, but motivations for research participation and informed consent were studied. Most respondents perceived the Rotterdam Study to be a health check. Other reasons mentioned were: to contribute to research, to be able to help others, and to be involved in the research project because others, neighbours, or family members, were also involved. Participants were also informed on results and publications of the Rotterdam Study, which helped to motivate participant involvement during and beyond the study.

\section{RESULTS}

\section{Study population}

A total of 5938 participants of the Rotterdam Study performed lung function measurements between 2009 and 2014. Of these, 4177 participants obtained brain MRI measurements and had interpretable DLCO measurements. A total of 4012 participants obtained brain MRI measurements and had interpretable spirometry measurements. A total of 1761 subjects were excluded because spirometry and DLCO tests were not interpretable, or because brain MRI measurements were not obtained. Those included were more often males, were younger, had a more severe smoking history, had a better kidney function and a better lung function (online supplemental table 1). Table 1 summarises the demographic

Table 1 Baseline characteristics by lung function group

\begin{tabular}{|c|c|c|c|c|}
\hline & Normal spirometry & COPD GOLD1 & COPD GOLD2-3 & $P$ value \\
\hline $\mathrm{N}$ & 3146 & 326 & 323 & \\
\hline Age (years) & $67.7 \pm 8.3$ & $68.5(8.2)$ & $69.9(9.1)$ & $<0.001$ \\
\hline Female sex (\%) & $1741(53.3)$ & $132(40.5)$ & $130(40.2$ & $<0.001$ \\
\hline $\mathrm{BMI}\left(\mathrm{kg} / \mathrm{m}^{2}\right)$ & $27.5 \pm 4.1$ & $26.2 \pm 3.7$ & $26.7 \pm 4.1$ & $<0.001$ \\
\hline Past smoking (\%) & $1717(54.6)$ & $186(57.1)$ & $170(52.6)$ & 0.523 \\
\hline Current smoking (\%) & $297(9.4)$ & $69(21.2)$ & $107(33.1)$ & $<0.001$ \\
\hline Pack-years (years) & $3.3(0.0,19.0)$ & $15.0(0.5,32.9)$ & $28.0(8.7,46.0)$ & $<0.001$ \\
\hline Haemoglobin (mmol/L) & $8.9 \pm 0.7$ & $9.0 \pm 0.7$ & $9.0 \pm 0.8$ & 0.005 \\
\hline Cholesterol (mmol/L) & $5.5 \pm 1.1$ & $5.4 \pm 1.1$ & $5.3 \pm 1.1$ & $<0.001$ \\
\hline Triglycerides (mmol/L) & $1.3(1.0,1.7)$ & $1.2(0.9,1.7)$ & $1.3(1.0,1.7)$ & 0.681 \\
\hline Glycaemia (mg/dL) & $5.7 \pm 1.2$ & $5.7 \pm 1.3$ & $5.8 \pm 1.1$ & 0.917 \\
\hline eGFR $\left(\mathrm{mL} / \mathrm{min} / 1.73 \mathrm{~m}^{2}\right)$ & $76.6 \pm 14.1$ & $75.8 \pm 14.6$ & $75.6 \pm 16.1$ & 0.341 \\
\hline ApoE high risk (\%) & $70(2.4)$ & $9(3.0)$ & $3(1.0)$ & 0.523 \\
\hline Hypertension (\%) & $2172(69.0)$ & $224(68.7)$ & $240(74.3)$ & 0.141 \\
\hline Antihypertensive medication (\%) & $1319(42.0)$ & $142(43.7)$ & $157(48.6)$ & 0.065 \\
\hline Type two diabetes (\%) & $420(13.5)$ & $52(16.1)$ & $58(18.1)$ & 0.044 \\
\hline $\mathrm{CHD}(\%)$ & $227(7.2)$ & $36(11.0)$ & $47(14.6)$ & $<0.001$ \\
\hline Heart failure (\%) & $49(1.6)$ & $5(1.5)$ & $24(7.5)$ & $<0.001$ \\
\hline Stroke (\%) & $0(0.0 \%)$ & $0(0.0 \%)$ & $0(0.0 \%)$ & NA \\
\hline Carotid artery stenosis (\%) & $202(6.5)$ & $26(8.0)$ & $42(13.4)$ & $<0.001$ \\
\hline Cerebral blood flow (mL/min) & $518.0 \pm 97.4$ & $514.7 \pm 91.6$ & $501.5 \pm 100.4$ & 0.014 \\
\hline Cerebral blood perfusion (mL/100 mL/min) & $55.7 \pm 9.6$ & $54.6 \pm 9.2$ & $54.31 \pm 10.0$ & 0.009 \\
\hline Brain volume $(\mathrm{mL})$ & $932.5 \pm 96.4$ & $946.4 \pm 97.2$ & $925.3 \pm 99.7$ & 0.015 \\
\hline
\end{tabular}

Data represented as mean $\pm \mathrm{SD}$, median (IQR) or count (percentage). Missing values are present for $\mathrm{CHD}(0.9 \%)$, kidney function (1.4\%). APOE, Apolipoprotein E; BMI, body mass index; CHD, coronary heart disease; COPD, chronic obstructive pulmonary disease; eGFR, estimated glomerular filtration rate; GOLD, Global initiative for Chronic Obstructive Lung Disease. 
Table 2 Cerebral blood flow values in different lung function categories

Cerebral blood flow ( $\mathrm{mL} / \mathrm{min})$

Unadjusted mean $\pm S D, p$ value

Adjusted $\beta(95 \% \mathrm{Cl}), \mathrm{p}$ value from linear regression analysis

COPD status $(n=3795)^{\star}$

Normal spirometry $(n=3146)$

518.0 (97.4), Ref

Ref.

COPD GOLD1 $(n=326)$

514.7 (92.0), 0.56

-3.9 (-14.1 to 6.3$), 0.45$

COPD GOLD2-3 ( $n=323)$

501.5 (100.4), <0.01

$-11.1(-21.7$ to -0.5$), 0.04$

COPD and CVD status $(n=3734) \dagger \ddagger$

Normal spirometry and no CVD $(n=2833)$

520.6 (96.8), Ref

Ref.

Normal spirometry and CVD $(n=264)$

489.8 (98.3), <0.01

-10.2 (-21.8 to 1.5$), 0.09$

COPD GOLD1 and no CVD ( $\mathrm{n}=283)$

518.6 (93.3), 0.74

-2.9 (-13.8 to 8.0$), 0.60$

COPD GOLD1 and CVD $(n=39)$

486.6 (81.6), 0.03

-20.9 (-48.9 to 7.1$), 0.14$

COPD GOLD2-3 and no CVD ( $\mathrm{n}=253)$

511.6 (98.5), 0.16

-7.7 (-19.4 to 3.9), 0.19

COPD GOLD2-3 and CVD $(n=62)$

465.9 (94.6), <0.01

-26.7 (-49.6 to -3.9$), 0.02$

Mean values \pm SD of cerebral blood flow $(\mathrm{ml} / \mathrm{min})$ per lung function category. $\mathrm{P}$ values for comparisons of mean values between two groups are derived from Student's t-test. Linear regression coefficients $(\beta)$ and $95 \% \mathrm{Cl}$ for differences in cerebral blood flow (mL/min) per lung function categories. Subjects with Preserved Ratio Impaired Spirometry (PRISm; $n=217$ ) excluded.

*Adjusted for age, sex, BMI, current smoking, haemoglobin, white cell count, glucose, eGFR, heart rate, hypertension, heart failure, coronary heart disease, diabetes and carotid artery stenosis.

†Adjusted for age, sex, BMI, current smoking, haemoglobin, white cell count, glucose, eGFR, heart rate, hypertension, diabetes and carotid artery stenosis.

$\ddagger$ Missing values are present for heart failure $(n=16)$, coronary heart disease $(n=16)$ and stroke $(n=71)$

$\mathrm{BMI}$, body mass index; COPD, chronic obstructive pulmonary disease; CVD, cardiovascular disease (heart failure and coronary heart disease); eGFR, estimated glomerular filtration rate; GOLD, Global initiative for Chronic Obstructive Lung Disease; PRISm, Preserved Ratio Impaired Spirometry.

and clinical characteristics of the overall study population (mean age $68.0 \pm 8.5$ years, $53 \%$ women) and stratified by lung function groups.

\section{Cerebral blood flow in subjects with and without COPD}

Multivariable adjusted linear regression analyses showed non-significantly lower values for cerebral blood flow in subjects with COPD GOLD1, and significantly lower values for cerebral blood flow in subjects with COPD GOLD2-3 compared with subjects with normal spirometry (table 2). The difference in cerebral blood flow in subjects with COPD GOLD2-3 was largest among those with a history of heart failure or coronary heart disease. In sex-stratified analyses, the decrease in cerebral blood flow in subjects with COPD GOLD2-3 compared with subjects with normal spirometry was statistically significant in women $(\beta-18.1$ (95\% CI -34.3 to -1.8$), \mathrm{p}=0.03)$, but not in men ( $\beta-5.7$ (95\% CI -19.8 to 8.4$), \mathrm{p}=0.43$ ). Notably, women exhibited lower values of multivariable adjusted cerebral blood flow ( $\beta-43.3$ (95\% CI -50.1 to -36.4$), p<0.01$ ), but higher values of cerebral blood perfusion ( $\beta 1.0$ (95\% CI 0.3 to 1.7$), \mathrm{p}<0.01)$.

Multivariable adjusted cerebral blood perfusion was not significantly lower, except in subjects with COPD GOLD2-3 with a history of heart failure or coronary heart disease (online supplemental table 2). The discrepancy between cerebral blood flow and cerebral blood perfusion in subjects with COPD GOLD2-3 was accompanied by differences in brain volume (multivariable adjusted brain volume in subjects with COPD GOLD1: $\beta 1.9$ (95\% CI -7.2 to 11.0$), p=0.68$ and COPD GOLD2-3: $\beta-10.5$ (95\% CI -19.9 to -1.0$), \mathrm{p}=0.03$ when compared with subjects with normal spirometry).

\section{Cerebral blood flow by lung function quintiles}

Subjects with $\mathrm{FEV}_{1}$, FVC, DLCO and DLCO/VA \% predicted values in the lowest quintile had significantly lower cerebral blood flow compared with subjects with values in the highest quintile (table 3). For FEV, FVC and DLCO \% predicted, these differences remained statistically significant after multivariable adjustment (figure 1, table 3). Subjects with FEV ${ }_{1}$, FVC, DLCO and DLCO/VA $\%$ predicted values in the lowest quintile had significantly lower cerebral blood perfusion as well. Differences for FEV1 and FVC \% predicted remained statistically significant after multivariable adjustment (online supplemental table 3).

Linear multivariable adjusted associations between $\mathrm{FEV}_{1}, \mathrm{FVC}$, DLCO and DLCO/VA \% predicted and cerebral blood flow or cerebral blood perfusion did not differ between sexes (range of $\mathrm{p}$ for interaction terms between 0.63 and 0.94$)$.

\section{Sensitivity analyses}

In order to ascertain that by measuring airflow limitation $(\mathrm{FEV} 1 / \mathrm{FVC}<0.7)$ we correctly specified subjects 
Table 3 Cerebral blood flow values in different lung function categories

Cerebral blood flow (mL/min)

Adjusted $\beta(95 \% \mathrm{Cl}), \mathrm{p}$ value from linear regression analysis

FEV1 \% predicted percentiles $(n=4012)$

$80-100$ th percentile $(n=803)$

\section{Mean $\pm S D, p$ value}

\begin{tabular}{|c|c|c|}
\hline 60-80th percentile $(n=801)$ & 522.2 (93.4), 0.31 & $-3.4(-12.1$ to 5.3$), 0.44$ \\
\hline 40-60th percentile $(n=803)$ & 519.4 (97.9), 0.85 & $-7.8(-16.5$ to 1.0$), 0.08$ \\
\hline 20-40th percentile $(n=803)$ & 513.5 (95.78), 0.31 & $-12.1(-20.9$ to -3.3$),<0.01$ \\
\hline 0-20th percentile $(\mathrm{n}=802)$ & 505.89 (102.6), 0.01 & $-17.7(-26.8$ to -8.6$),<0.01$ \\
\hline \multicolumn{3}{|c|}{ FVC $\%$ predicted percentiles $(n=4012)$} \\
\hline 80-100th percentile ( $n=803)$ & $519.7(98.2)$ & Ref \\
\hline $60-80$ th percentile $(n=803)$ & 519.0 (93.8), 0.88 & $-5.1(-13.8$ to 3.6$), 0.25$ \\
\hline 40-60th percentile $(n=802)$ & 524.5 (96.5), 0.33 & $1.2(-7.5$ to 10.0$), 0.78$ \\
\hline 20-40th percentile $(n=801)$ & 512.6 (99.7), 0.16 & $-11.9(-20.7$ to -3.1$),<0.01$ \\
\hline 0-20th percentile $(\mathrm{n}=803)$ & 503.56 (99.3), <0.01 & $-15.98(-24.8$ to -6.7$),<0.01$ \\
\hline \multicolumn{3}{|c|}{ DLCO \% predicted percentiles $(n=4177)$} \\
\hline 80-100th percentile ( $n=833$ ) & $512.7(95.0)$ & Ref. \\
\hline 60-80th percentile $(n=827)$ & 520.34 (99.9), 0.11 & 3.2 (-5.3 to 11.7$), 0.46$ \\
\hline 40-60th percentile $(n=838)$ & 521.6 (101.9), 0.06 & 2.9 (-5.7 to 11.5$), 0.51$ \\
\hline 20-40th percentile $(n=837)$ & 514.9 (96.9), 0.64 & $-3.3(-12.0$ to 5.3$), 0.45$ \\
\hline 0-20th percentile $(n=842)$ & 503.4 (93.45), 0.04 & $-14.0(-22.9$ to -5.0$),<0.01$ \\
\hline \multicolumn{3}{|c|}{ DLCO/VA \% predicted percentiles $(n=4177)$} \\
\hline 80-100th percentile ( $n=834)$ & 505.67 (96.9) & Ref. \\
\hline 60-80th percentile $(n=833)$ & $518.7(100.0),<0.01$ & 3.8 (-4.8 to 12.5$), 0.38$ \\
\hline 40-60th percentile $(n=834)$ & 516.0 (96.1), 0.03 & -0.2 (-9.0 to 8.6$), 0.96$ \\
\hline 20-40th percentile $(n=840)$ & 519.0 (97.9), <0.01 & 0.9 (-8.1 to 9.8$), 0.85$ \\
\hline 0-20th percentile ( $\mathrm{n}=836$ ) & 513.67 (96.9), 0.09 & $-8.4(-17.7$ to 0.9$), 0.08$ \\
\hline
\end{tabular}

Mean values \pm SD of cerebral blood flow $(\mathrm{mL} / \mathrm{min})$ per lung function group. P values for comparisons of mean values between two groups are derived from Student's t-test. Linear regression coefficients $(\beta)$ and $95 \% \mathrm{Cl}$ for differences in cerebral blood flow (ml/min) per lung function categories. Models are adjusted for age, sex, BMI, current smoking, haemoglobin, white cell count, glucose, eGFR, heart rate, hypertension, heart failure, coronary heart disease, diabetes and carotid artery stenosis. Bold values indicate statistically significant results $(p<0.05)$. Bold values indicate statistically significant results $(p<0.05)$

BMI, body mass index; DLCO, diffusion lung capacity for carbon monoxide; eGFR, estimated glomerular filtration rate; FEV1, forced expiratory volume in $1 \mathrm{~s}$; FVC, forced vital capacity; VA, alveolar volume.

with COPD, we repeated regression analyses after exclusion of subjects with a clinical diagnosis of asthma. The multivariable adjusted association between cerebral blood flow and COPD GOLD2-3 ( $\beta-11.1$ (95\% CI -21.7 to -0.5$), \mathrm{p}=0.04)$ persisted after exclusion of 338 subjects with asthma ( $\beta-12.6$ (95\% CI -24.1 to -1.1$)$, $\mathrm{p}=0.03$ ). The multivariable adjusted association between cerebral blood perfusion and COPD GOLD2-3 did not reach statistical significance in this subset $(\beta-1.0(95 \%$ CI -2.2 to 0.2$), p=0.10$ ). The associations between cerebral blood flow or cerebral blood perfusion and quintiles of FEV1, FVC, DLCO and DLCO/VA \% predicted did not fundamentally change after exclusion of subjects with asthma.

\section{DISCUSSION}

In this large population-based study, we demonstrated that subjects with COPD GOLD1 showed preserved values for cerebral blood flow when compared with subjects with normal spirometry. In contrast, subjects with COPD GOLD2-3 showed significantly reduced values for cerebral blood flow. The association between COPD GOLD2-3 and cerebral blood flow was influenced by underlying cardiovascular comorbidity, and was only statistically significant in women.

Cerebral blood flow was reduced in subjects with COPD GOLD2-3. Similarly, subjects with values for $\mathrm{FEV}_{1}$, FVC and DLCO \% predicted in the lowest quintiles had lowest cerebral blood flow. In these associations between lung function and cerebral blood flow, several risk factors 

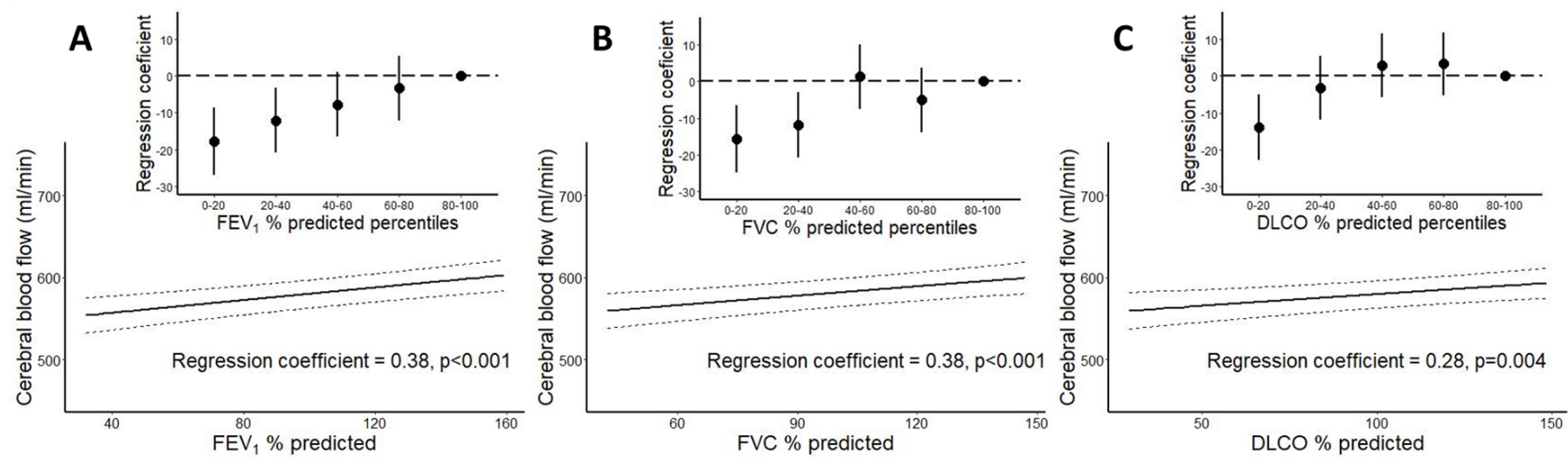

Figure 1 Cerebral blood flow according to lung function values. Cerebral blood flow according to lung function values. Regression lines with $95 \%$ Cls represent adjusted effects of FEV 1 (A), FVC (B) or DLCO (C) \% predicted on cerebral blood flow $(\mathrm{mL} / \mathrm{min})$. Error bars represent regression coefficients with 95\% Cls from linear regression analyses for cerebral blood flow $(\mathrm{mL} / \mathrm{min})$ in different Quintiles of FEV $1, F V C$ and DLCO \% predicted. Models are adjusted for age, sex, BMI, current smoking, haemoglobin, white cell count, glucose, eGFR, heart rate, hypertension, heart failure, coronary heart disease, diabetes and carotid artery stenosis. BMI, body mass index; DLCO, diffusion capacity of the lung for carbon monoxide; eGFR, estimated glomerular filtration rate; FEV1, forced expiratory volume in $1 \mathrm{~s}$; FVC, forced vital capacity.

negatively affecting parenchymal and endothelial integrity, as well as organ perfusion, are of great importance, and include ageing, cigarette smoking, unhealthy lifestyle, genetics and the presence of risk factors such as type 2 diabetes and cardiovascular disease including heart failure, coronary heart disease and carotid artery stenosis. ${ }^{3}$ We adjusted for many potential confounders, but still found a positive association. Possible explanations for the remaining effect will be further discussed and classify as residual confounding (eg, arterial stiffening, intracranial stenotic lesions) or a direct effect of COPD on cerebral blood flow (eg, through reduced left ventricular filling or hypoxia-induced endothelial disfunction).

Reductions in cerebral blood flow were largest in subjects with COPD GOLD2-3 that had cardiovascular comorbidities. These findings are consistent with previous reports of relatively preserved cerebral blood flow in patients with COPD, ${ }^{25-29}$ but impaired cerebral blood flow in patients with cardiovascular disease. ${ }^{27} 3031$ Atherosclerotic vascular disease in subjects with COPD may be a possible contributor of reduced cerebral blood flow. Previously, we showed aggravated extracranial-but not intracranial-carotid artery calcifications in subjects with COPD.$^{32}$ Hence, large artery atherosclerosis of the extracranial carotid arteries presumably contributes to impaired cerebral blood flow in these subjects, through both flow reducing effects of artery stenosis and vasodilatation limiting effects of arterial stiffening. Nevertheless, even after adjusting for extracranial carotid artery stenosis, we found a statistically significant association between COPD GOLD2-3 and cerebral blood flow. While previously not found to be more prevalent in subjects with $\mathrm{COPD},{ }^{32}$ intracranial stenotic lesions may still mediate some of the effect of lowered cerebral blood flow in subjects with COPD GOLD2-4 due to shared underlying risk factors. Moreover, despite being associated with both cardiovascular disease and cerebral blood flow,
ApoE status seemed not to be a confounder of the association between COPD and cerebral blood flow since it is not differential between participants with and without COPD. ${ }^{1}$

Previously, left ventricular filling was found to be reduced in subjects with COPD, apparently due to a smoking-induced subclinical loss of both lung parenchyma and pulmonary endothelium. ${ }^{13}$ Given that the pulmonary circulation is a high-flow, but low-pressure system, relatively modest reductions in the pulmonary capillary cross-sectional area may result in substantially limited left ventricular flow. ${ }^{13}$ Impaired left ventricular filling in turn may lead to reductions in cerebral blood flow. Hence, the association we observed between COPD GOLD2-3 and cerebral blood flow could indeed be driven by determinants of disturbed lung parenchymal and endothelial integrity, such as ageing and cigarette smoking, causing both COPD and left ventricular filling deficits leading to reduced cerebral blood flow. Alternatively, altered pulmonary oxygen uptake may result in arterial hypoxia, consequently negatively affecting cerebral circulation through the effects of hypoxia-induced endothelial dysfunction. ${ }^{5}$

Interpretation of cerebral blood flow in subjects with COPD is complicated by the fact that the cerebral vasculature is sensitive to changes in the partial pressure of $\mathrm{CO}_{2}$ and oxygen. During respiratory failure, hypercapniainduced cerebral vasodilatation increases $\mathrm{CO}_{2}$ washout from the brain and ascertains constant brain $\mathrm{pH}$ levels. ${ }^{33}$ Moreover, cerebrovascular dysfunction reflects the inability of the cerebral microvasculature to dilate in response to hypoxia or hypercapnia, and is endotheliumdependent. ${ }^{34}$ Impaired or blunted sensitivity to hypoxia has been shown with ageing, and in clinical conditions such as obstructive sleep apnoea, but not consistently in subjects with COPD. ${ }^{35} 36$ Cerebrovascular reactivity in response to hypercapnia diminishes with ageing as well, 
and is impaired in several brain conditions such as stroke, Alzheimer's disease and cognitive impairment, as well as in congestive heart failure and central sleep apnoea. ${ }^{33}$ Even in the early stages of COPD, the cerebrovascular responses to acute hypercapnia are reduced, a finding that was not restricted to hypercapnic patients only, ${ }^{37-41}$ although this has been contradicted by another study. ${ }^{42}$ Still, an inadequate cerebrovascular response in subjects with COPD may contribute to reduced cerebral blood flow, which may compromise cerebral oxygenation and pose a risk for cerebral ischaemia. ${ }^{35}$ However, participants of this study were recruited from the general population and represent a relatively healthy elderly population, unlikely to have respiratory failure at the time of the study visit. Therefore, our findings of reduced cerebral blood flow in subjects with COPD GOLD2-3 are unlikely to be primarily due to an impaired cerebrovascular response to acute hypercapnia, although long-term consequences of acute exacerbations cannot be ruled out.

A possible explanation for the positive association between lung function and cerebral blood flow but not with cerebral blood perfusion could be variability in brain size: a decline in cerebral blood flow may precede brain atrophy in elderly individuals resulting in an overestimated cerebral blood perfusion in subjects with impaired cerebral blood flow and established brain atrophy. ${ }^{7}$ Our findings of reduced brain volume in subjects with COPD GOLD2-3 support this hypothesis. However, longitudinal studies are needed to examine a possible causal relationship. In this context, lower cerebral blood flow has been associated with conditions such as dementia ${ }^{578}$ and cognitive decline. ${ }^{58}$

We observed a significant association between COPD and decreased cerebral blood flow only in women. The lack of an association between COPD and cerebral blood flow in men may be attributed to differences in underlying environmental and genetic risk factors. Also, we observed a higher cerebral blood perfusion in women as compared with men, consistent with previous reports, ${ }^{18} 43$ which persisted after multivariable adjustment. Several mechanisms have been previously postulated that could partly explain these sex discrepancies. Hypertension, more prevalent in men, reduces both the lumen diameter and the vessel number in the cerebral vasculature resulting in cerebral hypoperfusion. ${ }^{44}$ Moreover, angiotensin II has sexually dysmorphic effects on the cerebral vasculature with regard to vasoconstriction and susceptibility to vascular dysfunction, which are likely due to the protective effects of oestrogen in women. ${ }^{45}$ Oestrogen reduces atherosclerosis and counteracts the deleterious effects of hypertension on the cerebral circulation, through endothelial nitric oxide mediated vasodilatation and cyclooxygenase-dependent pathways. ${ }^{46}$ These effects may remain visible even after menopause, when oestrogen levels have dropped, such as in the elderly female participants of this study.

For the first time, we studied the link between lung function and cerebral circulation on a large population-based level, and by doing so, we provide important insights in lung-brain interactions. Strengths of this study are its population-based setting, large sample size, and availability of spirometry, DLCO and brain MRI measures of cerebral blood flow. The large number of participants included in this study allowed for multivariable adjustments in regression analyses, and by doing so, reduced the risk of confounding bias. Certain limitations must be taken into account. While the population-based nature of the Rotterdam Study minimises the risk for selection bias, results from the fifth round were used. Possibly, a healthy survival bias resulted in a dilution of the effect between predictor and outcome. Also, the cross-sectional design of our study did not allow us to examine causality. Third, additional adjustment for intracranial stenotic lesions or arterial $\mathrm{pO}_{2}$ and $\mathrm{pCO}_{2}$ might explain some of the remaining effect but we were unable to adjust for it. Finally, we could not adjust for genetic factors related to organ perfusion, which might affect both pulmonary and cerebral perfusion.

\section{CONCLUSION}

This is the first large population-based study investigating cerebral blood flow in subjects with and without COPD. We observed preserved cerebral blood flow in subjects with COPD GOLD1, and reduced values in COPD GOLD2-3. Decreased cerebral blood flow in subjects with COPD GOLD2-3 was influenced by underlying cardiovascular comorbidity. Future studies that aim to investigate the impact of impaired cerebral blood flow in patients with COPD on clinical outcomes should consider including cognitive function, lacunar infarcts and white matter lesions in the analyses.

\section{Author affiliations}

${ }^{1}$ Department of Respiratory Medicine, Ghent University Hospital, Ghent, Belgium ${ }^{2}$ Department of Epidemiology, Erasmus Medical Center, Rotterdam, the Netherlands ${ }^{3}$ Department of Bioanalysis, Ghent University, Gent, Belgium

${ }^{4}$ Department of Radiology and Nuclear Medicine, Erasmus Medical Center, Rotterdam, the Netherlands

${ }^{5}$ Department of Epidemiology, Harvard T. H. Chan School of Public Health, Boston, MA, USA

${ }^{6}$ Department of Respiratory Medicine, Erasmus Medical Center, Rotterdam, the Netherlands

${ }^{7}$ Department of Cardiology, Ghent University Hospital, Gent, Belgium

Acknowledgements The authors thank the study participants, the staff from the Rotterdam Study and the participating general practitioners.

Contributors Study design: DB, LL and MV; Data collection: SRAW, NT, LL and DB; Data-analysis and writing: SRAW and NT; Data interpretation: SRAW, NT and LL; Critical Review: GB, ER, MG, DB and MV. SRAW accepts as guarantor full responsibility for the work and/or the conduct of the study, had access to the data, and controlled the decision to publish.

Funding This research was funded by the 'Funds for Scientific Research Flanders (Fonds voor Wetenschappelijk Onderzoek Vlaanderen)', grant number 3G037618. The Rotterdam Study is supported by the Erasmus MC and Erasmus University Rotterdam; the Netherlands Organisation for Scientific Research (NWO); the Netherlands Organisation for Health Research and Development (ZonMW); the Research Institute for Diseases in the Elderly (RIDE); the Netherlands Genomics Initiative; the Ministry of Education, Culture and Science; the Ministry of Health, Welfare and Sports; the European Commission (DG XII); and the Municipality of 
Rotterdam. The funding sources had no involvement in the collection, analysis, writing, interpretation, or in the decision to submit the paper for publication.

Disclaimer The funding sources of the Rotterdam Study had no role in the study design, collection, analysis, and interpretation of data, in the writing of the report, nor in the decision to submit the paper for publication.

Competing interests SRAW: has, within the last 5 years, received a grant from GlaxoSmithKline. GB: Has, within the last 5 years, received honoraria for lectures from AstraZeneca, Boehringer-Ingelheim, Chiesi, GlaxoSmithKline, Novartis and Teva; he is a member of advisory boards for AstraZeneca, Boehringer-Ingelheim, GlaxoSmithKline, Novartis, Sanofi/Regeneron and Teva. ER: has, within the last 5 years, received research grants and/or speakers' fees from MSD, Amgen, Boehringer Ingelheim, Sanofi/Regeneron and Teva. LL: has, within the last 5 years, received respiratory society awards sponsored by AstraZeneca and Chiesi and performed expert consultation for Boehringer Ingelheim GmbH and Novartis. DB, MG, MV and NT have nothing to declare.

Patient consent for publication Consent obtained directly from patient(s)

Ethics approval This study involves human participants and was approved by the medical ethics committee of the Erasmus Medical Centre (Rotterdam, the Netherlands), and the review board of the Netherlands Ministry of Health, Welfare and Sports (1068889-159521-PG) approved the study.

Provenance and peer review Not commissioned; externally peer reviewed.

Data availability statement Data are available on reasonable request.

Supplemental material This content has been supplied by the author(s). It has not been vetted by BMJ Publishing Group Limited (BMJ) and may not have been peer-reviewed. Any opinions or recommendations discussed are solely those of the author(s) and are not endorsed by BMJ. BMJ disclaims all liability and responsibility arising from any reliance placed on the content. Where the content includes any translated material, BMJ does not warrant the accuracy and reliability of the translations (including but not limited to local regulations, clinical guidelines, terminology, drug names and drug dosages), and is not responsible for any error and/or omissions arising from translation and adaptation or otherwise.

Open access This is an open access article distributed in accordance with the Creative Commons Attribution Non Commercial (CC BY-NC 4.0) license, which permits others to distribute, remix, adapt, build upon this work non-commercially, and license their derivative works on different terms, provided the original work is properly cited, appropriate credit is given, any changes made indicated, and the use is non-commercial. See: http://creativecommons.org/licenses/by-nc/4.0/.

\section{ORCID iDs}

Sara R A Wijnant http://orcid.org/0000-0003-2995-0491

Lies Lahousse http://orcid.org/0000-0002-3494-4363

\section{REFERENCES}

1 Lahousse L, Vernooij MW, Darweesh SKL, et al. Chronic obstructive pulmonary disease and cerebral microbleeds. The Rotterdam study. Am J Respir Crit Care Med 2013;188:783-8.

2 Portegies MLP, Lahousse L, Joos GF, et al. Chronic obstructive pulmonary disease and the risk of stroke. The Rotterdam study. Am J Respir Crit Care Med 2016;193:251-8.

3 Lahousse L, Tiemeier H, Ikram MA, et al. Chronic obstructive pulmonary disease and cerebrovascular disease: a comprehensive review. Respir Med 2015;109:1371-80.

4 Lana F, Daniel B, Unal M. Global brain perfusion and the risk of transient ischemic attack and ischemic stroke: the Rotterdam study. J Am Heart Assoc 2019;8:e011565.

5 Wolters FJ, Zonneveld HI, Hofman A, Hazel Z I, Albert H, et al. Cerebral perfusion and the risk of dementia. Circulation 2017;136:719-28.

6 Sanchez DL, Thomas KR, Edmonds EC, et al. Regional hypoperfusion predicts decline in everyday functioning at three-year follow-up in older adults without dementia. JAD 2020;77:1291-304.

7 Ruitenberg A, den Heijer T, Bakker SLM, et al. Cerebral hypoperfusion and clinical onset of dementia: the Rotterdam study. Ann Neurol 2005;57:789-94.

8 Yew B, Nation DA, for the Alzheimer's Disease Neuroimaging Initiative. Cerebrovascular resistance: effects on cognitive decline, cortical atrophy, and progression to dementia. Brain 2017;140:1987-2001.

9 JBD V, Peng S-L, Chen X. Arterial-spin-labeling (ASL) perfusion MRI predicts cognitive function in elderly individuals: a 4-year longitudinal study. J Magn Reson Imaging 2018;48:449-58.
10 Kwater A, Gąsowski J, Gryglewska B, et al. Is blood flow in the middle cerebral artery determined by systemic arterial stiffness? Blood Press 2009;18:130-4.

11 Roeder M, Sievi NA, Kohlbrenner D. Arterial stiffness increases over time in relation to lung diffusion capacity: a longitudinal observation study in COPD. International Journal of Chronic Obstructive Pulmonary Disease (Epub ahead of print 23 January 2020).

12 Sheen SS, Kim HJ, Singh D, et al. Airflow limitation as a risk factor for vascular stiffness. int $j$ tuberc lung dis 2020;24:577-84.

13 Barr RG, Bluemke DA, Ahmed FS, et al. Percent emphysema, airflow obstruction, and impaired left ventricular filling. N Engl J Med 2010;362:217-27.

14 Ikram MA, Brusselle GGO, Murad SD, et al. The Rotterdam study: 2018 update on objectives, design and main results. Eur J Epidemiol 2017;32:807-50.

15 Quanjer PH, Stanojevic S, Cole TJ, et al. Multi-Ethnic reference values for spirometry for the 3-95-yr age range: the global lung function 2012 equations. Eur Respir J 2012;40:1324-43.

16 Wijnant SRA, De Roos E, Kavousi M, et al. Trajectory and mortality of preserved ratio impaired spirometry: the Rotterdam study. Eur Respir J 2020;55:1901217.

17 Graham BL, Brusasco V, Burgos F. ERS/ATS standards for single-breath carbon monoxide uptake in the lung. Eur Respir $J$ 2017;2017:1600016.

18 Vernooij MW, van der Lugt A, Ikram MA, et al. Total cerebral blood flow and total brain perfusion in the general population: the Rotterdam scan study. J Cereb Blood Flow Metab 2008;28:412-9.

19 Ikram MA, Vrooman HA, Vernooij MW. Brain tissue volumes in the general elderly population: the Rotterdam scan study. Neurobiol Aging 2008;29:882-90.

20 Leening MJG, Kavousi M, Heeringa J, et al. Methods of data collection and definitions of cardiac outcomes in the Rotterdam study. Eur J Epidemiol 2012;27:173-85

21 Berghout BP, Fani L, Heshmatollah A, Lana F, Alis H, et al. Vitamin D status and risk of stroke. Stroke 2019;50:2293-8.

22 Bots ML, Breslau PJ, Briët E, et al. Cardiovascular determinants of carotid artery disease. The Rotterdam elderly study. Hypertension 1992;19:717-20.

23 Levey AS, Stevens LA, Schmid CH, et al. A new equation to estimate glomerular filtration rate. Ann Intern Med 2009;150:604-12.

24 Licher S, Ahmad S, Karamujić-Čomić H, et al. Genetic predisposition, modifiable-risk-factor profile and long-term dementia risk in the general population. Nat Med 2019;25:1364-9.

25 Albayrak R, Fidan F, Unlu M, et al. Extracranial carotid Doppler ultrasound evaluation of cerebral blood flow volume in COPD patients. Respir Med 2006;100:1826-33.

26 Patterson JL, Heyman A, Duke TW. Cerebral circulation and metabolism in chronic pulmonary emphysema: with observations on the effects of inhalation of oxygen. Am J Med 1952;12:382-7.

27 Oliveira MF, Alencar MC, Arbex F, et al. Effects of heart failure on cerebral blood flow in COPD: rest and exercise. Respir Physiol Neurobiol 2016;221:41-8.

28 Yildiz S, Kaya I, Cece $\mathrm{H}$, et al. Impact of COPD exacerbation on cerebral blood flow. Clin Imaging 2012;36:185-90.

29 Vogiatzis I, Louvaris Z, Habazettl H, et al. Cerebral cortex oxygen delivery and exercise limitation in patients with COPD. Eur Respir J 2013;41:295-301.

30 Cornwell WK, Levine BD. Patients With Heart Failure With Reduced Ejection Fraction Have Exaggerated Reductions in Cerebral Blood Flow During Upright Posture *. JACC: Heart Failure 2015;3:176-9.

31 Alosco ML, Hayes SM. Structural brain alterations in heart failure: a review of the literature and implications for risk of Alzheimer's disease. Heart Fail Rev 2015;20:561-71.

32 Lahousse L, Bos D, Wijnant SRA, et al. Atherosclerotic calcification in major vessel beds in chronic obstructive pulmonary disease: the Rotterdam study. Atherosclerosis 2019;291:107-13.

33 Ogoh S. Interaction between the respiratory system and cerebral blood flow regulation. J Appl Physiol 2019;127:1197-205.

34 van Sloten TT, Sedaghat S, Carnethon MR, et al. Cerebral microvascular complications of type 2 diabetes: stroke, cognitive dysfunction, and depression. Lancet Diabetes Endocrinol 2020;8:325-36.

35 Beaudin AE, Hartmann SE, Pun M, et al. Human cerebral blood flow control during hypoxia: focus on chronic pulmonary obstructive disease and obstructive sleep apnea. J Appl Physiol 2017;123:1350-61.

36 Hartmann SE, Waltz X, Kissel CK, et al. Cerebrovascular and ventilatory responses to acute isocapnic hypoxia in healthy aging and lung disease: effect of vitamin C. J Appl Physiol 2015;119:363-73. 
37 Bernardi L, Casucci G, Haider T, et al. Autonomic and cerebrovascular abnormalities in mild COPD are worsened by chronic smoking. European Respiratory Journal 2008;32:1458-65.

38 Hartmann SE, Pialoux V, Leigh R, et al. Decreased cerebrovascular response to $\mathrm{CO}_{2}$ in post-menopausal females with COPD: role of oxidative stress. Eur Respir J 2012;40:1354-61.

39 Clivati A, Ciofetti M, Cavestri R, et al. Cerebral vascular responsiveness in chronic hypercapnia. Chest 1992;102:135-8.

40 de VM, WNJM C, der SMCV. Ventilatory and cerebrovascular responses in normocapnic and hypercapnic COPD patients. Eur Respir J 2001;18:61-8.

41 Flenley DC, Franklin DH, Millar JS. The hypoxic drive to breathing in chronic bronchitis and emphysema. Clin Sci 1970;38:503-18.
42 Erbland ML, Ebert RV, Snow SL. Interaction of hypoxia and hypercapnia on respiratory drive in patients with COPD. Chest 1990;97:1289-94.

43 Gur RC, Gur RE, Obrist WD, et al. Sex and handedness differences in cerebral blood flow during rest and cognitive activity. Science 1982;217:659-61.

44 Pires PW, Dams Ramos CM, Matin N, et al. The effects of hypertension on the cerebral circulation. Am J Physiol Heart Circ Physiol 2013;304:H1598-614.

45 De Silva TM, Faraci FM. Effects of angiotensin II on the cerebral circulation: role of oxidative stress. Front Physiol;3.

46 Girouard H, Lessard A, Capone C, et al. The neurovascular dysfunction induced by angiotensin II in the mouse neocortex is sexually dimorphic. Am J Physiol Heart Circ Physiol 2008;294:H156-63. 